\title{
INTERAKSI ASAM HUMAT DENGAN LARUTAN UREA, SP36 DAN KCL DAN PENGARUHNYA TERHADAP EFISIENSI PEMUPUKAN
}

\section{HUMAT ACID INTERACTION WITH UREA, SP36 AND KCI SOLUTIONS AND ITS EFFECT ON FERTILIZER EFFICIENCY}

\author{
Nurul Ismillayli, Siti Raudhatul Kamali, Saprini Hamdiani, Dhony Hermanto \\ Program Studi Kimia, Fakultas Matematika dan Ilmu Pendidikan Alam, Universitas Mataram \\ Email: nurul.ismillayli@unram.ac.id
}

Diterima: 28 September 2018. Disetujui: 02 Maret 2019. Dipublikasikan: 31 Maret 2019

\begin{abstract}
Abstrak: Telah dilakukan studi interaksi asam humat dengan larutan urea, super fosfat 36 (sp36), dan kalium klorida $(\mathrm{KCl})$ dengan menggunakan metode spektrofotometri Infra Red (IR). Penggunaan asam humat diketahui dapat meningkatkan ketersediaan, pengambilan nutrien pada tanaman dan efisiensi pemupukan urea, SP36 dan KCl. Akan tetapi, gugus fungsi asam humat yang berperan pada interaksi dengan pupuk belum dikaji. Penelitian dilakukan dengan menginteraksikan asam humat dan larutan pupuk urea, SP36 dan $\mathrm{KCl}$ dengan perbandingan massa 1:5. Interaksi asam humat dengan ketiga pupuk diketahui dengan membandingkan spektra IR asam humat murni dengan asam humat setelah bereaksi dengan ketiga pupuk. Adanya pergeseran serapan bilangan gelombang mengindikasikan terjadi interaksi. Pengaruh penambahan asam humat pada efisiensi pemupukan dilakukan dengan menghitung kadar nitrogen, fosfor dan kalium pada sampel tanaman jagung menggunakan metode Kjehdahl dan spektrofotometri UV-Vis. Hasil karakterisasi dengan spektrofotometer Fourier Transform Infra Red (FTIR) menunjukkan bahwa struktur hipotetik asam humat memiliki gugus fungsional $-\mathrm{OH}$, alifatis, eter, aromatis dan karboksilat. Interaksi asam humat dengan ketiga pupuk terjadi pada gugus fenol, aromatis dan karboksilat yang ditunjukkan dengan adanya pergeseran serapan pada daerah $3421 \mathrm{~cm}^{-1}, 1611 \mathrm{~cm}^{-1}$ dan $1375 \mathrm{~cm}^{-1}$. Penambahan asam humat pada pemupukan dasar dapat meningkatkan efisiensi pemupukan.
\end{abstract}

Kata kunci: Asam humat, Urea, SP36, KCl, spektrofotometer FTIR, efisiensi pemupukan.

\begin{abstract}
Interaction studies of humic acid with urea solution, super phosphate 36 (sp36), and potassium chloride $(\mathrm{KCl})$ have been carried out using Infra Red (IR) spectrophotometry method. The use of humic acid is known to increase availability, take nutrients in plants and fertilize urea, SP36 and KCl. However, the functional groups of humic acid which play a role in the interaction with fertilizers have not been studied. The study was conducted by interacting humic acid and urea fertilizer solution, SP36 and $\mathrm{KCl}$ with a mass ratio of $1: 5$. The interaction of humic acid with all three fertilizers is known by comparing the IR spectra of pure humic acid with humic acid after reacting with all three fertilizers. There is a shift in absorption of wave numbers indicating interaction. The effect of humic acid on fertilization efficiency was carried out by calculating the levels of nitrogen, phosphorus and potassium in samples of corn plants using the Kjehdahl method and UV-Vis spectrophotometry. Fourier Transform Infra Red (FTIR) spectra showed that the hypothetical structure of humic acid has functional groups of $-\mathrm{OH}$, aliphatic, ether, aromatic and carboxylic. The interaction of humic acid with the three fertilizers occurs in phenol, aromatic and carboxylic groups as indicated by a shift in absorption in $3421 \mathrm{~cm}^{-1}, 1611 \mathrm{~cm}^{-1}$ and $1375 \mathrm{~cm}^{-1}$ regions. Addition of humic acid to basic fertilization could improve fertilization efficiency.
\end{abstract}

Keywords: Humic acid, urea, SP36, KCl, FTIR spectrophotometer, fertilizer efficiency

\section{PENDAHULUAN}

Telah diketahui bahwa pupuk anorganik dapat merangsang pertumbuhan tanaman dengan meningkatkan kandungan unsur hara dalam tanah, akan tetapi penggunaan tanpa adanya bahan organik dalam jangka panjang dan berlebihan dapat menyebabkan perubahan struktur tanah, pemadatan, kandungan unsur hara dalam tanah menurun, dan pencemaran lingkungan. Selain itu efektivitas penggunaannya juga dinilai rendah. Sebagai contoh penggunaan urea sebagai sumber nitrogen. Walaupun mudah diaplikasikan dan banyak tersedia, urea sangat mudah mengikat air dan mudah larut maka pupuk ini mudah tersedia dan segera menguap. Akibatnya dimungkinkan urea yang diaplikasikan pada tanah hilang lewat pelindian, penguapan, dan runoff. Begitu juga dengan SP36 , unsur hara fosfor yang terdapat dalam pupuk SP-36 hampir seluruhnya larut dalam air sehingga dimungkinkan saat diaplikasikan di 
tanah ada bagian yang hilang terbawa air. Dilaporkan akumulasi residu unsur -unsur kimia seperti N, P, dan $\mathrm{K}$ dalam tanah akibat dari pemakaian pupuk anorganik yang berlebihan dan terus-menerus sekitar $50 \%$ nitrogen, $40 \%$ - $75 \%$ potassium, dan $5 \%$ - $25 \%$ fosfat mengendap di lahan pertanian, pada tubuh perairan, dan air tanah [1]

Peningkatan efisisiensi penggunaan pupuk anorganik telah banyak dilakukan. Diantaranya penggunaan asam humat yang dikombinasikan dengan urea dan fosfat terbukti dapat meningkatkan pembentukan $\mathrm{NH}_{4}^{+}$ dibanding $\mathrm{NH}_{3}$ sehingga dapat mengurangi pencemaran lingkungan dan tingkat kematian bakteri nitrifikasi [2]. Hermanto dkk [3] melaporkan bahwa asam humat secara signifikan dapat meningkatkan ketersediaan dan pengambilan nutrien (N,P,K, dan C-organik) pada tanaman jagung di lahan kering. Kadar nutrien pada buah dan batang tanaman jagung juga meningkat. Turan et al. [4] melaporkan bahwa asam humat sebagai pelengkap pupuk dapat meningkatkan pertumbuhan tanaman jagung pada tanah dengan kadar garam tinggi (soil-salinity condition). Chen dan Aviad [5], Varanini dan Pinton [6] juga telah meneliti efek positif humat pada perkecambahan benih, pertumbuhan semai bibit, inisiasi dan pertumbuhan akar, perkembangan tunas dan pengambilan nutrisi makro dan mikro tanaman. Humat sebagi komponen utama bahan organik tanah mempunyai efek langsung dan tidak langsung pada pertumbuhan tanaman [7]. Efek langsung asam humat pada jaringan tumbuhan menghasilkan berbagai hasil biokimia, sedangkan efek tidak langsung meliputi peningkatan sifatsifat tanah seperti aggregasi, aerasi, permeabilitas, kapasitas menahan air, transport dan ketersediaan mikronutrien [8].

Asam humat memiliki kemampuan sebagai ligan yang dapat mengikat hara dalam bentuk kompleks yang dapat menyimpan sementara dalam tanah dan melepaskannya ketika tanaman membutuhkan. Kemampuan asam humat ini tidak terlepas dari keberadaan gugus-gugus aktif yang dimilikinya seperti $\mathrm{COOH}$, aromatis dan $-\mathrm{OH}$ fenolik [9]. Interaksi gugus-gugus ini dengan pupuk tersebut menarik untuk dikaji, terutama untuk modifikasi strukturnya dalam upaya peningkatan kapasitas sebagai slow realease fertilizer. Pada penelitian ini akan dipelajari interaksi asam humat dengan urea, SP36 dan $\mathrm{KCl}$ dengan menggunakan metode adsorpsi dan dikarakterisasi dengan menggunakan spektrofotometer FTIR. Interaksi asam humat dengan ketiga pupuk dapat diketahui dengan membandingkan spektra IR asam humat murni dengan asam humat setelah bereaksi dengan pupuk. Adanya pergeseran bilangan gelombang mengindikasikan interaksi yang lebih kuat dari sekedar interaksi elektrostatis antara gugus pada asam humat dengan ketiga pupuk, dimungkinkan interaksi terjadi melalui pembentukan. Pengaruh penggunaan asam humat bersama pupuk dasar terhadap efisiensi pemupukan juga akan dikaji.

\section{METODE PENELITIAN}

Bahan-bahan yang digunakan adalah akuades, kertas saring Whatman 42, asam humat (Aldrich), Urea (46\%) produk pupuk BontangKalimantan Timur, SP-36, dan KCl. Peralatan yang digunakan meliputi alat-alat gelas standar dan spektrofotometer FTIR Perkin Elmer.

Penelitian dilakukan dengan membuat larutan urea, larutan SP36 d larutan $\mathrm{KCl}$ dengan melarutkan masing-masing 1,0 gram pupuk ke dalam $50 \mathrm{~mL}$ akuades. Larutan di saring untuk memisahkan filtrat dengan pengotor dengan menggunakan kertas whatman 42. Larutan yang terbentuk diinteraksikan dengan asam humat dengan perbandingan massa 1:5. Campuran digojok dengan menggunakan shaker selama 24 jam pada suhu ruang. Campuran dipisahkan dan residu yang diperoleh dikeringkan pada suhu ruang. Sejumlah tertentu residu dikarakterisasi menggunakan spektrofotometer FTIR dengan menggunakan metode pellet $\mathrm{KBr}$.

Pengaruh penambahan asam humat pada efisiensi pemupukan dilakukan berdasarkan metode sebelumnya [3]. Kadar nitrogen dalam sampel ditentukan menggunakan metode Kjehdahl sedangkan kadar kalium dan fosfor ditentukan menggunakan metode spektrofotometri uv-vis. Efisiensi pemupukan dihitung dengan menggunakan persamaan (1) berikut

$E(\%)=\frac{S_{\text {perlakuan }}-S_{\text {kontrol }}}{D} \times 100 \%$

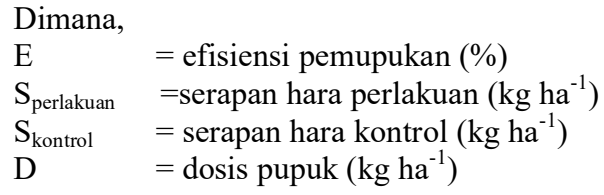

\section{HASIL DAN PEMBAHASAN}

Karakterisasi asam humat, humat-urea, humat-SP36 dan humat-KCl dengan menggunakan spektrofotometer FTIR disajikan pada Gambar 1 dan Tabel 1. Munculnya pita serapan pada daerah $3421 \mathrm{~cm}^{-1}$ menunjukkan adanya gugus $\mathrm{OH}$ pada asam humat. Intensitasnya yang kuat dan melebar biasanya disebabkan oleh adanya ikatan hidrogen intramolekuler dalam molekul asam humat [10]. Adanya gugus alkohol pada asam humat diperkuat dengan munculnya regangan $\mathrm{C}-\mathrm{O}$ alkohol dan polisakarida pada serapan $1032 \mathrm{~cm}^{-}$ 1. Keberadaan C-H alifatis ditunjukkan oleh serapan pada $2927 \mathrm{~cm}^{-1}$, sedangkan bahu pada $2850 \mathrm{~cm}^{-1}$ dengan intensitas rendah adalah regangan $\mathrm{C}-\mathrm{H}$ pada $\mathrm{O}-\mathrm{CH}_{3}$ eter yang merupakan 
karakteristik dari lignin dan produk degradasi lignin. Keberadaan eter ini diperkuat dengan adanya serapan pada $1096 \mathrm{~cm}^{-1}$ dan serapan tajam pada $912 \mathrm{~cm}^{-1}$ yang mengindikasikan eter siklik dan karbohidrat. Vibrasi $\mathrm{C}=\mathrm{C}$ aromatis dan regangan $\mathrm{C}=\mathrm{O}$ pada gugus $\mathrm{COO}^{-}$terdeteksi pada daerah $1611 \mathrm{~cm}^{-1}$. Serapan pada $1375 \mathrm{~cm}^{-1}$ merupakan deformasi $\mathrm{OH}$ dan regangan $\mathrm{C}-\mathrm{O}$ pada fenol dan gugus $\mathrm{COO}^{-}$[11]. Serapan ini bersama dengan serapan pada daerah $1611 \mathrm{~cm}^{-1}$ mengindikasikan adanya gugus karboksilat, dimungkinkan karena adanya abu dalam asam humat. Kandungan abu dalam asam humat bervariasi 3-4\%, akan tetapi perubahan kecil pada kualitas dan kuantitasnya dapat meyebabkan perubahan asam karboksilat menjadi bentuk garamnya [12]. Berdasarkan data spektra IR, struktur hipotetik asam humat memiliki gugus fungsional $-\mathrm{OH}$, alifatis, eter, aromatis dan karboksilat.

Ketika urea dilarutkan dalam air, urea akan mengalami hidrolisis menjadi ammonium karbonat yang akan terurai lebih lanjut menjadi ion ammonium dan karbondioksida, sesuai reaksi (1) dan (2) berikut

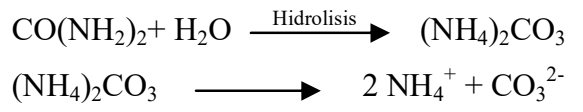

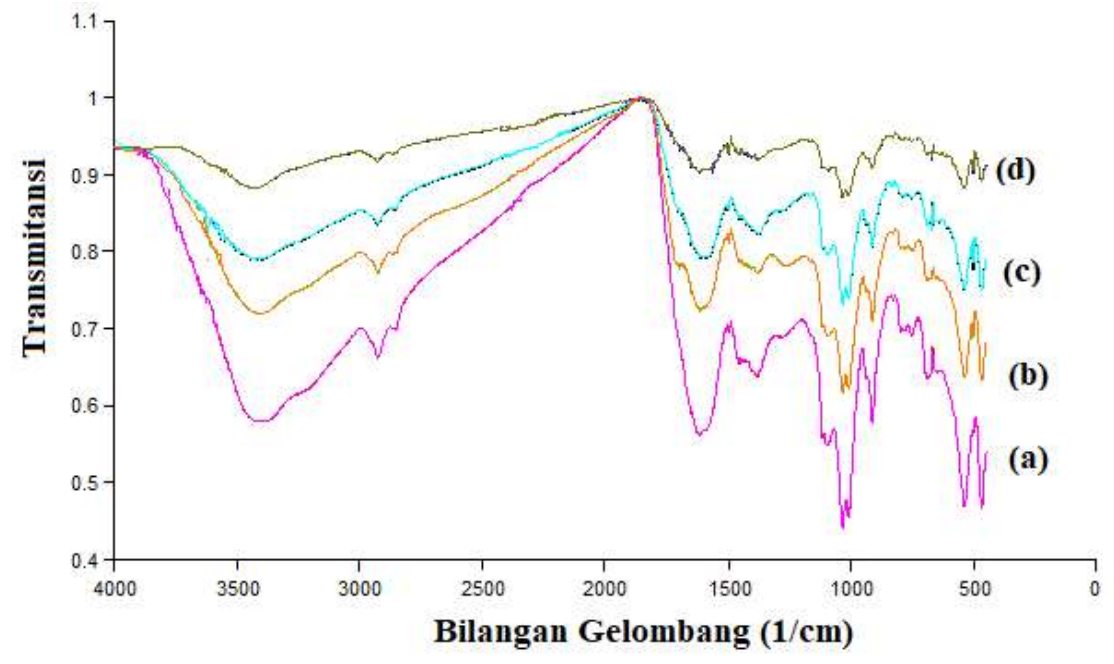

Gambar 1 Spekta FT-IR (a) AH (b) humat- urea, (c) humat- SP36- dan (d) humat- KCl

Tabel 1 Bilangan Gelombang dan Gugus fungsi humat-urea, humat-SP36 dan humat-KCl

\begin{tabular}{lcccc}
\hline \multicolumn{2}{c}{ Gugus Fungsi } & \multicolumn{4}{c}{ Bilangan Gelombang $\left(\mathrm{cm}^{-1}\right)$} \\
\cline { 2 - 5 } & Asam Humat & Humat- urea & Humat- SP36 & Humat-KCl \\
\hline vibrasi $-\mathrm{OH}$ & 3421,33 & 3401,47 & 3403,70 & 3450,03 \\
vibrasi C-H alifatis & 2927,90 & 2926,19 & 2926,96 & 2927,90 \\
$\begin{array}{l}\text { vibrasi C-H pada O-CH }{ }_{3} \text { eter } \\
\text { vibrasi C=C aromatis, C=O }\end{array}$ & 2850,35 & 2850,35 & 2850,35 & 2850,35 \\
$\begin{array}{l}\text { asimetris pada COOH } \\
\text { vibrasi C=O pada COO }\end{array}$ & 1611,19 & 1616,09 & 1615,22 & 1559,96 \\
$\begin{array}{l}\text { vibrasi C-O eter } \\
\text { vibrasi C-O pada }\end{array}$ & 1375,59 & 1380,27 & 1376,46 & 1379,90 \\
$\begin{array}{l}\text { alkohol/polisakarida } \\
\text { vibrasi C-O pada eter siklik dan }\end{array}$ & 1096,60 & 1096,48 & 1096,60 & 1096,60 \\
karbohidrat & 1032,90 & 1033,06 & 1032,16 & 1032,31 \\
virasi C-C=O & 912,96 & 912,67 & 912,15 & 912,20 \\
\hline
\end{tabular}

Interaksi asam humat $\begin{aligned} & \text { dengan } \\ & \text { dengan }\end{aligned}$
ammonium $\left(\mathrm{NH}_{4}^{+}\right)$ditunjukkan herbedaan spektra asam humat dengan humat-
$\mathrm{NH}_{4}^{+}$seperti pada Gambar 1 dan Tabel 1.
Pergeseran pada serapan $3421 \mathrm{~cm}^{-1}$ menjadi 3401
$\mathrm{~cm}^{-1}$ menunjukkan ada interaksi gugus $-\mathrm{OH}$ pada
asam humat dengan $\mathrm{NH}_{4}^{+}$. Pergeseran juga
terjadi pada serapan di daerah $1611 \mathrm{~cm}^{-1}$ dan $^{-1}$
$1375 \mathrm{~cm}^{-1}$ menjadi $1616 \mathrm{~cm}^{-1}$ dan $1380 \mathrm{~cm}^{-1}$
vang menoindikasikan adanva interaksi $\mathrm{NH}_{4}^{+}$ dengan gugus aromatis dan karboksilat pada asam humat. Gugus hidroksil, aromatis dan karboksilat merupakan gugus aktif asam humat. Suntari et,al [9] juga melaporkan terjadi ikatan antara gugus aromatis pada asam humat dengan $\mathrm{NH}_{4}^{+}$dari urea. Hal ini diindikasikan dengan adanya pergeseran bilangan gelombang 1631,67 $\mathrm{cm}^{-1}$ menjadi $1625,88 \mathrm{~cm}^{-1}$ (Urea-humat 260 ppm). Kerapatan elektron yang tinggi pada gugus-gugus ini dimungkinkan herikatan dengan 
$\mathrm{NH}_{4}^{+}$. Adanya ikatan ini menyebabkan pelepasan ammonium menjadi lebih lambat sehingga asam humat-urea dapat dimanfaatkan sebagai slow release fertilizer. Interaksi pada ikatan asam humat dengan ammonium dapat terjadi melalui ikatan kovalen atau ikatan hidrogen (untuk gugus karboksilat dan fenol) [11]. Ikatan kovalen menghasilkan senyawa yang lebih stabil dibanding ikatan hidrogen. sesuai reaksi (3)

Pupuk $\mathrm{KCl}$ dalam air akan terionisasi

$$
\mathrm{KCl} \longrightarrow \mathrm{K}^{+}+\mathrm{Cl}^{-}
$$

Interaksi asam humat dengan $\mathrm{K}^{+}$ ditunjukkan dengan perbedaan spektra asam humat dengan humat-KCl seperti pada Gambar 1 dan Tabel 1. Interaksi humat- $\mathrm{K}^{+}$serupa dengan interaksi humat- $\mathrm{NH}_{4}{ }^{+}$, yaitu terjadi pada gugus fenol, karboksilat dan aromatis pada asam humat dengan $\mathrm{K}^{+}$dari $\mathrm{KCl}$. Interaksi ini ditunjukkan dengan adanya pergeseran pada serapan 3421 $\mathrm{cm}^{-1}, 1611 \mathrm{~cm}^{-1}$ dan $1375 \mathrm{~cm}^{-1}$ menjadi $3450 \mathrm{~cm}^{-}$ ${ }^{1} 1559 \mathrm{~cm}^{-1}$ dan $1379 \mathrm{~cm}^{-1}$.

Interaksi humat- SP36 agak berbeda dibanding dengan kedua pupuk sebelumnya. Pupuk SP36 termasuk pupuk superfosfat, bila dilarutkan dalam air akan mengalami reaksi (4)

$\mathrm{Ca}\left(\mathrm{H}_{2} \mathrm{PO}_{4}\right)_{2} \rightleftarrows \mathrm{Ca}^{2+}+2 \mathrm{H}_{2} \mathrm{PO}_{4}^{-}$
Pupuk ini merupakan tergolong pupuk yang lambat tersedia. Oleh sebab itu untuk meningkatkan kelarutan pupuk tersebut perlu diberi asam seperti asam humat. Pemberian asam humat selain memperbaiki sifat kimia tanah juga mampu meningkatkan kelarutan dari pupuk karena asam organik tersebut akan mengikat $\mathrm{Ca}$ dari senyawa $\mathrm{Ca}\left(\mathrm{H}_{2} \mathrm{PO}_{4}\right)_{2}$, sehingga ion $\mathrm{H}_{2} \mathrm{PO}_{4}^{-}$ bisa terlepas dan tersedia bagi tanaman [13]. Di dalam tanah asam humat dapat mencegahan fiksasi fosfor oleh $\mathrm{Al}$ dan $\mathrm{Fe}$ sehingga fosfor lebih tersedia bagi tanaman. Dengan pemberian asam humat, kation penjerap $\mathrm{P}$ selanjutnya membentuk kompleks logam-organik sehingga ortofosfat terlepas dari ikatan logam-P dan menjadi tersedia bagi tanaman [14] [15] [16]. Oleh karenanya yang terdeteksi oleh spektrofotometer FTIR adalah interaksi asam humat dengan $\mathrm{Ca}^{2+}$ dari pupuk SP36. Interaksi ini terjadi pada gugus fenol, aromatis dan karboksilat, mengingat gugus ini kerapatan elektronnya tinggi sehingga dimungkinkan berikatan dengan ion $\mathrm{Ca}^{2+}$. Interaksi ditunjukkan dengan adanya pergeseran pada serapan 3421 $\mathrm{cm}^{-1}, 1611 \mathrm{~cm}^{-1}$ dan $1375 \mathrm{~cm}^{-1}$.

Interaksi asam humat dengan ketiga jenis pupuk berimplikasi pada efisiensi pemupukan. Penggunaan asam humat sebagai pelengkap pupuk pada tanaman jagung dapat meningkatkan efisiensi pemupukan $[3,17]$ seperti tampak pada Gambar 2.

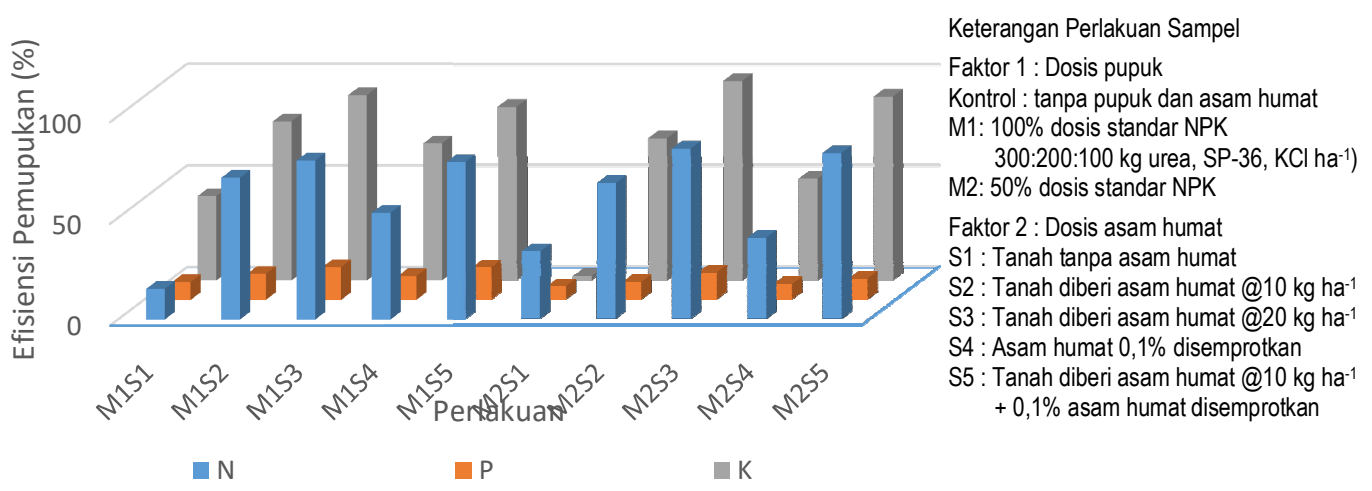

Gambar 2 Efisiensi Pemupukan N,P dan K

Efisiensi pemupukan merupakan kemampuan tanaman untuk menyerap unsur hara makro (N,P dan K) yang terkandung dalam pupuk. Pemupukan N,P dan K tanpa asam humat memberikan nilai efisiensi di bawah $50 \%$ (perlakuan M1S1), menunjukkan bahwa unsur hara $(\mathrm{N}, \mathrm{P}$ dan $\mathrm{K})$ yang terserap oleh tanaman lebih sedikit dibanding dengan yang tidak terserap. Unsur hara makro yang tidak terserap oleh tanaman dimungkinkan terbawa oleh air atau menguap. Aplikasi asam humat pada tanah terbukti meningkatkan efisiensi pemupukan dengan nilai tertinggi didapat pada pemberian asam humat $20 \mathrm{~kg} \mathrm{ha}{ }^{-1}$ bahkan efisiensi pemupukan yang lebih tinggi dicapai pada dosis nınık vano lehih rendah
Asam humat dapat memperlambat pola pelepasan nitrogen dari pupuk sehingga kehilangan pupuk yang diakibatkan oleh penguapan dan pencucian semakin kecil dan tanaman memperoleh kesempatan menyerap nitrogen lebih banyak. Asam humat dapat mencegahan fiksasi fosfor oleh $\mathrm{Al}$ dan $\mathrm{Fe}$ dalam tanah sehingga fosfor lebih tersedia bagi tanaman. Dengan pemberian asam humat, kation penjerap $\mathrm{P}$ selanjutnya membentuk kompleks logam-organik sehingga ortofosfat terlepas dari ikatan logam-P dan menjadi tersedia bagi tanaman. Peningkatan ketersediaan kalium juga berpengaruh positif terhadap peningkatan efisiensi pemupukan. 
Fosfor memiliki nilai efisiensi pemupukan paling kecil diantara unsur hara makro lain untuk seluruh tanaman. Hal ini menunjukkan bahwa unsur fosfor merupakan unsur yang paling sulit terserap oleh tanaman. Sebaliknya kalium merupakan unsur hara yang paling mudah terserap oleh tanaman, diindikasikan oleh nilai efisiensi pemupukan kalium yang mencapai 90,75\%.

\section{KESIMPULAN}

Hasil karakterisasi FTIR menunjukkan bahwa struktur hipotetik asam humat memiliki gugus fungsional $-\mathrm{OH}$, alifatis, eter, aromatis dan karboksilat. Sedangkan interaksi asam humat dengan ketiga pupuk $\left(\mathrm{NH}_{4}^{+}, \mathrm{K}^{+}\right.$, dan $\left.\mathrm{Ca}^{2+}\right)$ terjadi pada gugus fungsi fenol, aromatis dan karboksilat pada asam humat yang ditunjukkan dengan adanya pergeseran serapan pada daerah $3421 \mathrm{~cm}^{-1}, \quad 1611 \mathrm{~cm}^{-1}$ dan $1375 \mathrm{~cm}^{-1}$. Penambahan asam humat pada pemupukan dasar dapat meningkatkan efisiensi pemupukan.

\section{DAFTAR PUSTAKA}

[1] Karwan, A. Salikin. (2003). Sistem Pertanian Berkelanjutan. Kanisius. Yogyakarta.

[2] Ahmed, O.H., H. Ammuddin and M.H.A. Husni. (2006). Effects of Urea, Humic Acids and Phosphate Interactions in Fertilizer Micro sites on Ammonia Volatilization and Soil Ammonium and Nitrate Contents. International Journal of agricultural Research. 1(1): 25-31.

[3] Hermanto, Dharmayani N.K.T., D., Kurniasih R., Kamali, S.R. (2013). Pengaruh Asam Humat sebagai Pelengkap Pupuk pada Tanaman Jagung terhadap Efisiensi Pemupukan di Lahan Kering Kec. BayanNTB. Jurnal Ilmu Pertanian. 16(2) 28-41.

[4] Turan M.A., Asik B.B., Katkat A.V., Celik H (2011). The Effects of Soil-Applied Humic Substances to the Dry Weight and Mineral Nutrient Uptake of Maize Plants under SoilSalinity Conditions. Not Bot Hort Agrobot Cluj, 39(1):171-177.

[5] Chen Y., Aviad T., (1990). Effect of Humic Substances on Plant Growth, p. 161-187. In: MacCarthy P, Clapp CE, Malcolm RL, Bloom PR (Eds.). Humic substances in soil and crop sciences: selected reading. Soil Science Society Am, Madison.

[6] Varanini Z., Pinton R. (1995). Humic substances and plant nutrition. Prog Bot 56:97-117.

[7] Sangeetha M., Singaram P., Devi R.D. 2006. Effect of lignite humic acid and fertilizers on the yield of onion and nutrient availability. Proceedings of 18th World Congress of Soil Science July 9-15. Philadelphia, Pennsylvania, USA.

[8] Tan K.H., (2003), Humic Matter in Soil and Environment, Principles and Controversies. Marcel Dekker, Inc., Madison, New York.

[9] Suntari, R., Retnowati, R., Soemarno. Muir, M., (2013). Study on the Release of NAvailable $\left(\mathrm{NH}_{4}{ }^{+}\right.$and $\left.\mathrm{NO}_{3}{ }^{-}\right)$of Urea-Humate. International Journal of a Agriculture and Forestry 3(36) : 209-219.

[10] Samat dan A. Lebani. (2012). Studi Interaksi Seng (II) pada Asam Humat Muara Kuang serta Aplikasinya terhadap Limbah Industri Pelapisan seng. Jurnal Penelitian sains. Vol. 15 nomor 1 (C) 22-25.

[11] Tan, K.H. (1991). Principle of Soil Chemistry (Dasar-Dasar Kimia Tanah) (Alih bahasa: Didiek Hadjar Goenardi) Gadjah Mada University Press. Yogyakarta. P 295.

[12] Takács, M. and Alberts, J.J. (1999). Changes in Chemical Compositian, FTIR and Fluorescence Spectral Characteristics of Humic Acids in Peat Profiles. (in Understanding Humic Substances, Edited by E.A. Ghabbour and G. Davies, The Royal Society of Chemistry, Boston. Pp 171-172.

[13] Premono M.E. (1998). Mikrob pelarut fosfat untuk mengefisienkan pupuk fosfat dan prospeknya di Indonesia. Hayati. Jurnal Biosains 5 (4) : 89-94.

[14] Jones, J.B., Jr, B. Wolf, and H.A. Mills. (1991), Plant Analysis Handbook. A Practical Sampling, Preparation, Analysis, and Interpretation Guide. Micro-Macro Pub, Inc.

[15] Hardjowieno, S. 1992. Ilmu Tanah. Media Tama Sarana Perkasa. Jakarta. p 233.

[16] Havlin, J.L., J.D. Beaton, S.L. Tisdale and W.L. Nelson. (1999). Soil Fertility and Fertilizer: An Introduction to Nutrient Management. Prentice Hall Inc. Upper Saddle River. New Jersey. Pp 86-153.

[17] Hermanto, D., Kamali, S. R., Kurnianingsih, R., dan Ismillayli, N. (2014). Optimalisasi Lahan Kering Kecamatan Bayan-Lombok Utara Menggunakan Asam Humat Terimmobil dalam Rumput Laut sebagai Pelengkap Pupuk pada Tanaman Jagung (Zea Mays L). Sains Tanah-Journal of Soil Science and Agroclimatology, 10(2), 101112. 